\title{
Metastable Secondary Structures in Ribosomal RNA Molecular Hysteresis in the Acid-Base Titration of Escherichia coli Ribosomal RNA
}

\author{
Arnold Revzin $\dagger$, Eberhard Neumann $\ddagger$ and Aharon Katchatsky \\ Polymer Department, The Weizmann Institute of Science, Rehovot, Israel
}

(Received 12 February 1973, and in revised form 29 May 1973)

\begin{abstract}
The metastable conformational states which underlie the hysteresis displayed by Escherichia coli ribosomal RNA in its $\mathrm{pH}$ titration in the acid range have been analyzed in terms of acid-stable RNA secondary structures. Sedimentation measurements show that the phenomenon is intramolecular, so that analysis of the hysteresis loops can, in principle, reveal details of molecular architecture. Hysteresis cycles obtained spectrophotometrically and potentiometrically were compared for RNA in solutions of different ionic strengths and ionic compositions. The effect is much smaller at lower ionic strength and disappears in the absence of magnesium ions. The curve followed upon addition of acid appears to reflect the equilibrium state of the system at each $\mathrm{pH}$ value. On the "base branch" of the loop, a slow absorbance change (complete in hours) was observed after the $\mathrm{pH}$ was raised by addition of a portion of base. This slow procoss is attributed to the annealing of "mismatched" multihelical regions of the ribosomal RNA. Certain regions, however, remain in metastable configurations for days and it is these long-lived non-equilibrium structures that underlie the hysteresis. Titration at $35^{\circ} \mathrm{C}$ gave hysteresis loops of the same size and shape as at $20^{\circ} \mathrm{C}$; indeed, we found that the metastabilities are not removed even at $80^{\circ} \mathrm{C}$. Ultraviolet light absorbance difference spectra at $80^{\circ} \mathrm{C}$ between solutions at the same $\mathrm{pH}$, but on different branches of the cycle, give insight into the nature of the metastable conformation(s).

Our experimental observations lead us to propose that the hysteresis is due to the formation at acidic $\mathrm{pH}$ of double-helical structures involving protonated guanine and adenine base pairs. The $G \cdot G$ pairs seem especially important to account for the very high thermal stability, as well as for the fact that the structures formed at a given $\mathrm{pH}$ value as acid is added dissociate only at higher $\mathrm{pH}$ values when the solution is titrated with base. Titrations of transfer RNA, along with literature data on $16 \mathrm{~S}$ rRNA primary structure, imply that the metastable regions in rRNA may consist of porhaps 10 to 15 boso pairs.
\end{abstract}

\section{Introduction}

An unusual feature of certain ribosomal RNAs is the existence of true hysteresis phenomena in their pH titrations in the acid range (Everett, 1967; Cox \& Littauer, 1963; Cox, 1966; Cox \& Katchalsky, 1972). That is, the oplicul density (or proton

$\uparrow$ To whom correspondence should be addressed at the Institute of Molecular Biology, University of Oregon, Eugene, Ore. 97403, U.S.A.

† Present address: Max-Planck-Institut für biophysikalische Chemie, D-34 Göttingen, Germany.

$\S$ This work was initiated under the guidance and inspiration of the late Aharon Katchalsky. We regret that the final form of the manuscript did not benefit from his critical insight and comments. 
binding) versus $\mathrm{pH}$ data lie on one curve when the $\mathrm{pH}$ is lowered by addition of acid, and on a different curve when the $\mathrm{pH}$ is raised by addition of base. One obtains a closed loop, which can be reproduced on suecessive titration cycles. The loop exists between definite $\mathrm{pH}$ limits, while above and below these limits only a single reversible curve is observed. "Scanning" curves (Everett, 1967; Cox \& Katchalsky, 1972) and loops within the main loop can also be obtained.

Hysteresis loops for rRNA reflect the presence of long-lived metastable conformational states and non-equilibrium transitions in the system (Cox \& Katchalsky, 1972). We shall show that the phenomenon is an intramolecular one so that analysis of the hysteresis can in principle yield information about the structure of individual RNA molecules. It is generally accepted that at $\mathrm{pH} 7 \mathrm{rRNA}$ is composed of a series of double-helical domains (of from 4 to 20 base pairs) separated by single-stranded regions (containing about 3 to 10 residues) (Doty et al., 1959; Cox, 1966; Spirin \& Gavrilova, 1969). The double-helical regions are probably of the Watson-Crick type (Timasheff et al., 1961; Arnott et al., 1966). It seems likely that at lower $\mathrm{pH}$ values there may be rearrangements to different types of hase-paired regions, and we may infer which structures are likely by considering the properties of model polynucleotides.

Cox \& Katchalsky (1972) have discussed rRNA hysteresis qualitatively by using a hypothetical nucleotide sequence devised by Cox (1966). This hypothetical sequence has the same over-all base composition as rRNA, and the arrangement of the residues allows the formation of acid-stable regions at low $\mathrm{pH}$ values. All features of the real hysteresis cycle, such as the smooth loop and the existence of scanning curves, were interpreted in terms of possible conformations of the hypothetical RNA. Cox \& Katchalsky (1972) observed that the hysteresis may well be due to the prevention of the nucleation step in the formation of a (equilibrium) double-helical region; the barrier could arise because of metastability in the "low $\mathrm{pH}$ " structures which prevents nucleation by immobilizing the appropriate bases in non-equilibrium configurations.

A quantitative analysis of RNA titration behavior, based on extensive new u.v.absorbance and proton-binding data, will be given in another paper (Revzin, Neumann \& Katchalsky, manuscript in preparation). The primary goal of the current study was to ascertain which of the conformations that RNA regions can assume in solution may be metastable and thus underlie the hysteresis.

\section{Materials and Methods}

\section{(a) Materials}

The rRNA was a mixture of $16 \mathrm{~S}$ and $23 \mathrm{~S}$ particles prepared from fresh $70 \mathrm{~S} \mathrm{E}$. coli ribosomes (strain MRE600) which were a gift from Dr D. Elson. The ribosomes were isolated using the protocol in Spitnik-Elson \& Atsmon (1969), and the nucleic acid was extracted following the sodium dodecyl sulfate-phenol procedure described by Eilam \& Elson (1971). After treatment with dodecyl sulfate, the RNA was purificd by extraction 2 or 3 times with phenol and chloroform. After precipitation from distilled ethanol containing $2 \%$ potassium acetate, the RNA was dialyzed against several changes of sterile distilled water. The dialysis bags had been sterilized by autoclaving. The concentrated RNA solution was lyophilized and the dry RNA stored in small portions at $-20^{\circ} \mathrm{C}$. Nucleic acid solutions for titration were prepared from individual small portions of dried material immediately before starting experiments. The integrity of the RNA, as judged 
from sedimentation boundary analysis, was maintained even after several freezingthawing cycles. All RNA solutions were slowly filtered through sterile Millipore filters. Lowry analysis showed that residual protein was less than $1 \%$. The preparation procedure described above was used to prepare two large batches of rRNA.

Transfer RNA (mixture from $E$. coli strain $\mathrm{K} 12 \mathrm{~W} 6, \mathrm{~T}_{1}$ ribonuclease free) was a gift of Dr U. Z. Littauer.

\section{(b) Buffers}

Buffers were prepared from analytical grade reagents used without further purification. All buffer solutions were autoclaved before use. Strict sterility was observed in preparation and handling of solutions and glassware. Sterile water was obtained by autoclaving water which had been doubly distilled from permanganate. Absorbance cuvettes were sterilized by immersion in $6 \mathrm{~N}-\mathrm{HNO}_{3}$ for 5 to $10 \mathrm{~min}$ followed by thorough rinsing with sterile water. Glassware was treated either by the nitric acid process or by heating at $160^{\circ} \mathrm{C}$ for several hours. New plastic gloves were worn whenever relevant. Experiments in which these precantions were not observed inevitably resulted in failure.

\section{(c) Potentiometric titrations}

Potentiometric titrations were performed with a Motrohm EAl47 combined microelectrode and a Radiometer $\mathrm{pH}$ meter 26, using a cell of special design, which minimized the risk of bacterial contamination while permitting the electrode and the titrants to be easily introduced. The vessel was immersed in a water bath, and stirring was effected magnetically. A nitrogen atmosphere was maintained above the surface of the solution to prevent $\mathrm{CO}_{2}$ absorption. The electrode was sterilized immediately before use by dipping it several times into $6 \mathrm{~N}-\mathrm{HNO}_{3}$ and rinsing with sterile water; tests showed that this had no adverse effect on electrode performance.

Approximately $10.5 \mathrm{ml}$ of solution, having an RNA concentration about $4 \times 10^{-3}$ $\mathrm{M}-[\mathrm{P}] \dagger$, were titrated in each experiment. The ionic composition of the solution was $0 \cdot 099$ M-NaCl, 0.001 M-sodium cacodylate. The exact amount of solution was determined by weighing the vessel before and after filling. The phosphate concentration was determined spectrophotometrically, using an extinction coefficient for RNA, $\epsilon_{260}=7450 \mathrm{~cm}^{-1} \mathrm{M}$ $[P]^{-1}\left(T=20^{\circ} \mathrm{C}\right.$, wavelength, $\lambda,=260 \mathrm{~nm}$ ) (Littauer \& Eisenberg, 1959). For these measurements, 50 or $100 \mu \mathrm{l}$ RNA solution were diluted into a weighed amount (about $2.5 \mathrm{ml}$ ) of buffer. A "blank" solution, containing buffer, but not RNA, was titrated in each experiment.

Acid $(\mathrm{HCl})$ and base $(\mathrm{NaOH})$ were $0 \cdot 1 \mathrm{M}$ and were added from Agla syringes with Teflon needles; the syringe calibrations were checked against weighed amounts of standard phthalatc solution. (Some problems were encountered with evaporation from the junctions between syringe parts-this was reduced to a tolerable level by sealing the exposed parts of the syringes with a light grease.)

After sufficient titrant was added to change the $\mathrm{pH}$ by about 0.25 unit, the $\mathrm{pH}$ was recorded as a function of time. No significant drifts in $\mathrm{pH}$ were observed. It should be noted that any changes in $\mathrm{pH}$ due to uptake or release of protons via a slow reaction of the RNA would have been masked at high $\mathrm{pH}$ by the presence of $0.001 \mathrm{M}$-sodium cacodylate buffer and at low $\mathrm{pH}$ by the buffering capacity of the solvent itself.

\section{(d) Spectrophotometric titrations}

Spectrophotometric titrations were performed in a Zeiss PMQII spectrophotometer. The $\mathrm{pH}$ was determined simultaneously with the absorbance by placing a Metrohm combined microelectrode in the cuvette, out of the light path. The electrode was sterilized immediately before use, as described above. Temperature was controlled with a Zeiss thermostatically controlled cell block. Titrants were added from Agla microsyringes fitted with long Teflon needles and stirring was achieved by a Zeiss stirring motor unit combined with a small magnetic stirrer in the cuvette. After sufficient titrant was added to change the $\mathrm{pH}$ by the desired amount (usually 0.2 to $0.5 \mathrm{pH}$ unit) the absorbance spectrum was

† Abbreviation used: [P] denotes phosphate residues of the polynucleotide backbone. 
read at appropriate time intervals until no further change in absorbance with time was observed. The RNA concentration was about $10^{-4} \mathrm{M}-[\mathrm{P}]$ for these experiments.

\section{(e) Sedimentation measurements}

Sedimentation coefficients were determined with a Beckman model E ultracentrifuge, equipped with u.v.-absorbance optics and a photnelectric scanner. The RNA solutions were the same as those used in the spectrophotometric titrations $\left([\mathrm{P}] \sim 10^{-4} \mathrm{M}\right)$. Measurements were taken at a rotor speed of $32,000 \mathrm{revs} / \mathrm{min}$ and the rotor temperature was maintained at $20^{\circ} \mathrm{C}$.

\section{(f) Absorbance difference spectra at $80^{\circ} \mathrm{C}$}

Absorbance difference spectra for two RNA solutions at the same $\mathrm{pH}$ but on different branches of the hysteresis loop were determined over the temperature range 20 to $80^{\circ} \mathrm{C}$. About $2.5 \mathrm{ml}$ of freshly prepared RNA solution $\left(10^{-4} \mathrm{M}-[\mathrm{P}], 0.099 \mathrm{M}-\mathrm{NaCl}, 0.001 \mathrm{M}\right.$ sodium cacodylate, $2 \times 10^{-4} \mathrm{M}-\mathrm{MgCl}_{2}, \mathrm{pH} 7$ ), were transferred to each of two spectrophotometric cuvettes (of about $4 \mathrm{ml}$ capacity). A solution on the "acid branch" was obtained by titrating the material in one cuvette with acid directly to the $\mathrm{pH}$ of interest (e.g. $\mathrm{pH} 4.0$ ), then adding $50 \mu \mathrm{l}$ of sodium acetate-acetic acid buffer $\left(0.1 \mathrm{M}\right.$ in $\mathrm{Na}^{+}$) to control the $\mathrm{pH}$ at the desired value. The material in the second cuvette was titrated with acid to $\mathrm{pH} 3.0$ or 2.8 (titration time about 15 to $30 \mathrm{~min}$ ); after 10 to $15 \mathrm{~min}$ at the low $\mathrm{pH}$, base was added slowly to bring this "base branch" solution to $\mathrm{pH} 4 \cdot 0$, and $50 \mu \mathrm{l}$ of buffer were added. The optical density was monitored throughout each titration. The solutions were then left for at least $10 \mathrm{~h}$ to be certain that slow changes in absorbance with time (especially for the base branch solution) had levelled off. (It was thus possible to check that we had successfully produced solutions at the same $\mathrm{pH}$ on the acid and base branches of the hysteresis loop, a necessary precaution since for unknown reasons titrations occasionally ended in failure.) About $1 \mathrm{ml}$ of each of the two solutions was transferred to smaller cuvettes. These cuvettes, loosely stoppered, were placed in a thermostatically controlled cell block and heated to about 80 to $85^{\circ} \mathrm{C}$ using a Haako tompcraturo regulator. The absorbance of each solution was read at approximately $10 \mathrm{deg}$. C intervals while heating and cooling. The highest temperatures were maintained for as short a time as possible to minimize degradation of the RNA. Total time for a heating-cooling cycle was 2 to $2.5 \mathrm{~h}$. Cuvettes were weighed before and after heating-losses due to evaporation were less than $0.5 \%$. Some experiments were performed by placing the cells in a cell block preheated to the desired temperature, reading the absorbance after equilibration, then rapidly cooling the solutions to $20^{\circ} \mathrm{C}$.

The effect of EDTA on acid and base branch solutions was checked by preparing such solutions at $\mathrm{pH} 4$ and then adding excess EDTA to a final concentration of about $5 \times 10^{-3}$ M. After slow absorbance changes had levelled off, absorbance difference spectra were determined for these solutions at elevated temperatures and also upon recooling.

\section{Results}

\section{(a) Potentiometric titrations}

The results of the potentiometric titrations are presented in Figure 1. As noted in the Introduction, the base branch curves followed upon titration with base from low $\mathrm{pH}$ do not coincide with the acid branch curve obtained when titrating with acid from $\mathrm{pH}$ 7. Addition of acid to a solution which has undergone a full titration cycle gives a curve which is coincident with the first acid branch. This indicates that after the hysteresis cycle has been completed the RNA has returned to its original ( $\mathrm{pH} 7$ ) configuration.

The number of protons bound was calculated by considering the difference in amount of titrant needed to bring the nucleic acid and "blank" solutions to the same pH value (Tanford, 1962, p. 76). Since a study of the hysteresis phenomenon requires 


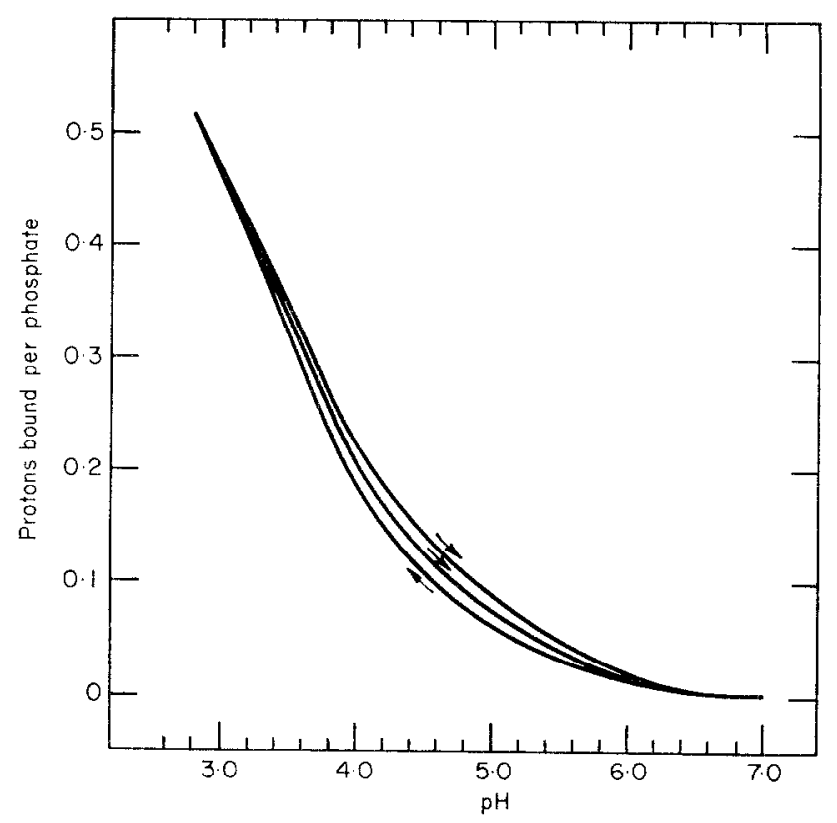

FIG. 1. Potentiometric titration of unfractionated $E$. coli rRNA. Experimental conditions: $T=20^{\circ} \mathrm{C}$; buffer; $0.099 \mathrm{M}-\mathrm{NaCl}, 0.001 \mathrm{~m}$-sodium cacodylate; RNA concentralion, $\sim 4 \times 10^{-3}$ M-[P]. These data were derived using RNA from our first preparation (see text) which apparently contained sufficient residual $\mathrm{Mg}^{2+}$ to show the full hysteresis effect. The three curves are: lower curve, acid branch; upper curve, base branch from $\mathrm{pH} 2.8$; middle curve, scanning curve from pH $3 \cdot 2$.

more than one acid-base cycle to be performed on a single solution, the computations require more extended relations than is usually the case. We denote the nucleic acid solution by a superscript $N$ and the "blank" by a superscript $B$, and we let $V_{\mathrm{H}}^{\mathrm{i}}, V_{\mathrm{OH}}^{\mathrm{i}}$ be the volumes of acid (molarity $\mathrm{M}_{\mathrm{H}}$ ) and of base (molarity $\mathrm{M}_{\mathrm{OH}}$ ), respectively, added to solution i. Also, let $V_{0}$ be the initial volume of each ( $\mathrm{pH}$ 7) starting solution. If we make the good assumption that the activity coefficient of $\mathrm{H}^{+}, \gamma_{\mathrm{H}+}$, at a particular hydrogen-ion concentration is independent of the presence of nucleic acid, then when the RNA and the blank solutions have the same $\mathrm{pH}$, the general equation for the number of protons bound, $\Delta n$, is

$$
\begin{aligned}
\Delta n= & \frac{1}{V_{0}+V_{\mathrm{H}}^{\mathrm{B}}+V_{\mathrm{OH}}^{\mathrm{B}}} \\
& {\left[V_{0} \mathbf{M}_{\mathrm{H}}\left(V_{\mathrm{H}}^{\mathrm{N}}-V_{\mathrm{H}}^{\mathrm{B}}\right)-V_{0} \mathbf{M}_{\mathrm{OH}}\left(V_{\mathrm{OH}}^{\mathrm{N}}-V_{\mathrm{OH}}^{\mathrm{B}}\right)-\left(\mathbf{M}_{\mathrm{H}}+\mathbf{M}_{\mathrm{OH}}\right)\left(V_{\mathrm{H}}^{\mathrm{B}} V_{\mathrm{OH}}^{\mathrm{N}}-V_{\mathrm{H}}^{\mathrm{N}} V_{\mathrm{OH}}^{\mathrm{B}}\right)\right] . }
\end{aligned}
$$

Note that $\Delta n=0$ for the starting solution.

On the first acid branch of the titration, $V_{\mathrm{OH}}^{\mathrm{B}}=V_{\mathrm{OH}}^{\mathrm{N}}=0$, and the number of protons bound at any $\mathrm{pH}$ is

$$
\Delta n=\frac{1}{V_{0}+V_{\mathrm{H}}^{\mathrm{B}}}\left[V_{0} \mathbf{M}_{\mathrm{H}}\left(V_{\mathrm{H}}^{\mathrm{N}}-V_{\mathrm{H}}^{\mathrm{B}}\right)\right],
$$

where $V_{\mathrm{H}}^{\mathrm{N}}$ and $V_{\mathrm{H}}^{\mathrm{B}}$ are the volumes of acid needed to bring the two solutions to that $\mathrm{pH}$ value. 
Calculations for the base branch are simplified if the same volume of acid is added to each solution before base is added. This makes $V_{H}^{\mathrm{N}}=V_{\mathrm{H}}^{\mathrm{B}}$ at each point on the base branch, and

$$
\Delta n=\frac{1}{V_{0}+V_{\mathrm{H}}^{\mathrm{R}}+V_{\mathrm{OH}}^{\mathrm{R}}}\left[V_{0} \mathrm{M}_{\mathrm{OH}}+V_{\mathrm{H}}^{\mathrm{B}}\left(\mathrm{M}_{\mathrm{H}}+\mathrm{M}_{\mathrm{OH}}\right)\right] \cdot\left(V_{\mathrm{OH}}^{\mathrm{B}}-V_{\mathrm{OH}}^{\mathrm{N}}\right),
$$

$V_{\mathrm{OH}}^{\mathrm{N}}$ and $V_{\mathrm{OH}}^{\mathrm{B}}$ being the volumes of base added to bring the two solutions to the $\mathrm{pH}$ of interest. Similarly, before adding acid again equal volumes of basc are added to each solution. Then, for the second acid branch we have

$$
\Delta n=\frac{1}{V_{0}+V_{\mathrm{H}}^{\mathrm{B}}+V_{\mathrm{OH}}^{\mathrm{B}}}\left[V_{0} \mathbf{M}_{\mathrm{H}}+V_{\mathrm{OH}}^{\mathrm{B}}\left(\mathbf{M}_{\mathrm{H}}+\mathbf{M}_{\mathrm{OH}}\right)\right] \cdot\left(V_{\mathrm{H}}^{\mathrm{N}}-V_{\mathrm{H}}^{\mathrm{B}}\right) .
$$

Equations for subsequent base or acid branch titrations on the same solution can be written by inspection, using the above equations as guides.

Equations (2a) to (2c) are virtually exact expressions that facilitate rapid calculation of $\Delta n$. We have computed $\Delta n$ by comparing the nucleic acid and blank solutions at the same $\mathrm{pH}$ value (rather than using differences in $\mathrm{pH}$ for " $\mathrm{N}$ " and " $\mathrm{B}$ " solutions to which equal volumes of titrant have been added). Our procedure eliminates the need to know the value of $\gamma_{\mathrm{H}+}$, and also minimizes any liquid junction potential or glass electrode correction differences between the two solutions (Steinhardt \& Beychock, 1964, p. 158).

Values for $\Delta n$ computed using equations (2a) to (2c) were converted to $\mathrm{H}^{+}$bound per phosphate (denoted by $\mathrm{H}^{+} /[\mathrm{P}]$ ) using the concentration determined by procedures described under Materials and Methods.

\section{(b) Spectrophotometric titrations}

The results of the spectrophotometric titrations are presented in Figures 2 and 3. The u.v.-absorbance, $A_{\lambda}$, was recorded at six wavelengths, and was corrected for dilution from addition of titrant. For the sake of comparison, absorbance readings were all converted to those for an equivalent solution of nucleotide concentration $10^{-4} \mathrm{M}$-[P]. Different experiments gave loops which were reproducible in size and shape to \pm 0.004 absorbance unit. Figures 2 and 3 show both the boundary loops of the hysteresis cycle and selected scanning curves. Scanning curves are obtained from both branches of the loop. The acid branch is reversible to $\mathrm{pH} 3.8$ (i.e. the hysteresis is seen only if the back titration is started from $\mathrm{pH}<3 \cdot 8$ ).

It is difficult to determine accurately the actual point of closure of the loops as higher $\mathrm{pH}$ is reached upon titration with base. Even small increases in absorbance, due perhaps to limited hydrolysis of the RNA (Cox, 1968) can displace the closure point by, say, $0.5 \mathrm{pH}$ unit. It is found that the loops are closed somewhere between $\mathrm{pH} 5$ and $\mathrm{pH}$ 6. As in the potentiometric titrations, after a cycle was completed the system followed the lower curve upon further addition of acid, indicating that the RNA had returned to its initial $\mathrm{pH} 7$ configuration.

\section{(c) Time independence of hysteresis loops}

Figure 4(a) represents the low $\mathrm{pH}$ section of a spectrophotometric titration cycle at $I=0.1$ M (in the presence of $\mathrm{Mg}^{2+}$ ions, see below). Let us consider the addition of base to a solution at point $\mathrm{P}$ (say, at $\mathrm{pH} \mathrm{3.5}$ ) on the base branch of the loop. The 

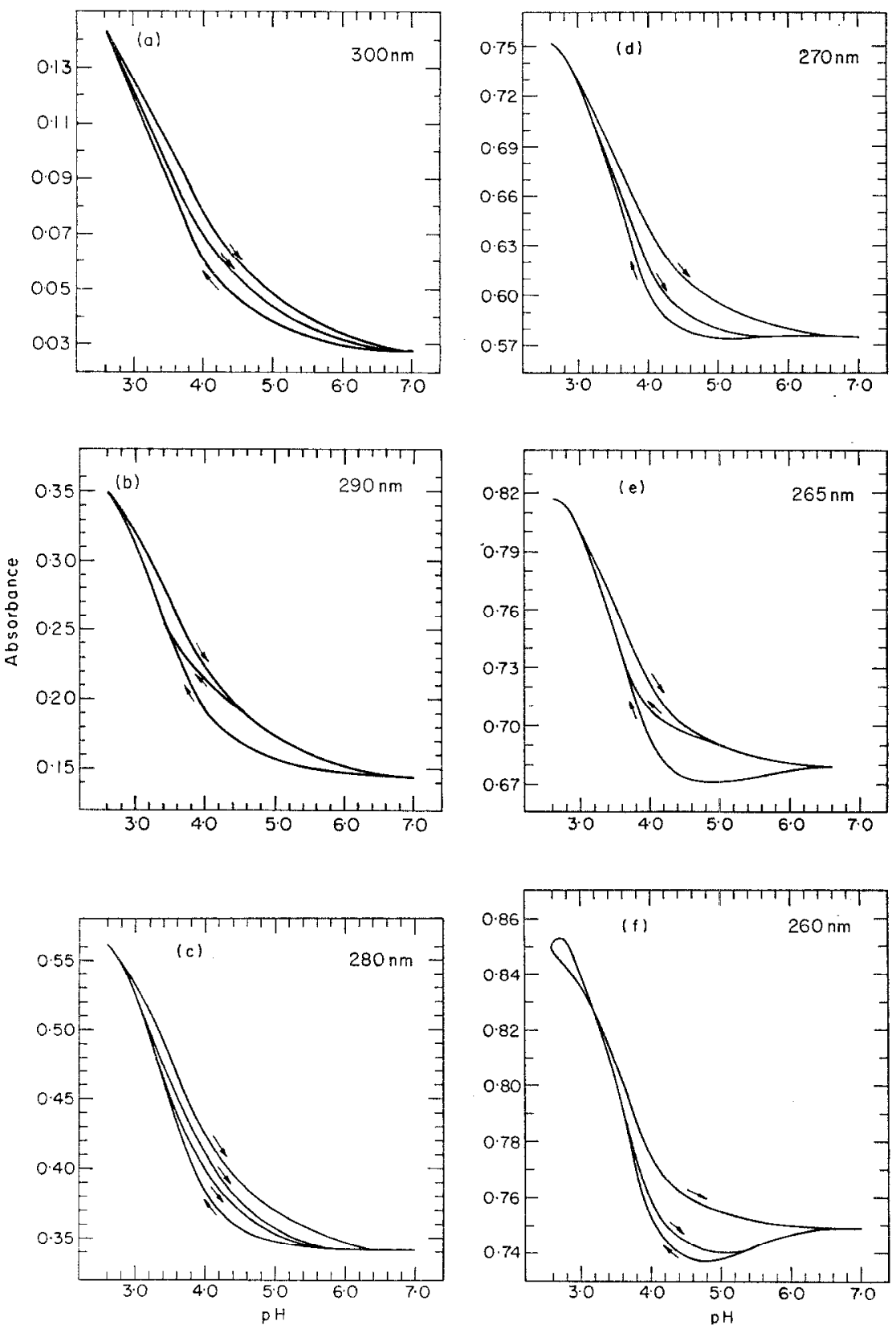

FIG. 2. Spectrophotometric titration of unfractionated E. coli rRNA. Experimental conditions: $T=20^{\circ} \mathrm{C}$; buffer, $0.099 \mathrm{M}-\mathrm{NaCl}, 0.001 \mathrm{M}$-sodium cacodylate, $\sim 2 \times 10^{-4} \mathrm{M}^{-\mathrm{MgCl}_{2}}$. (Identical curves were obtained with our first RNA preparation, without the addition of $\mathrm{Mg}^{2}+$ ions (see text).) All data have been converted to a standard RNA concentration of $10^{-4} \mathrm{M}$-[P]. For each of the six wavelengths shown, the lower curve is the acid branch of the hysteresis loop and the upper curve is the base branoh from $\mathrm{pH} \mathbf{2 \cdot 6}$. Intermediate curves are selected scanning curves from the acid or base branches. No hysteresis is observed unloss tho $\mathrm{pH}$ is dcercasod below $\mathrm{pH} 3 \cdot 8$. Curves are for time-independent absorbance readings (see text). 

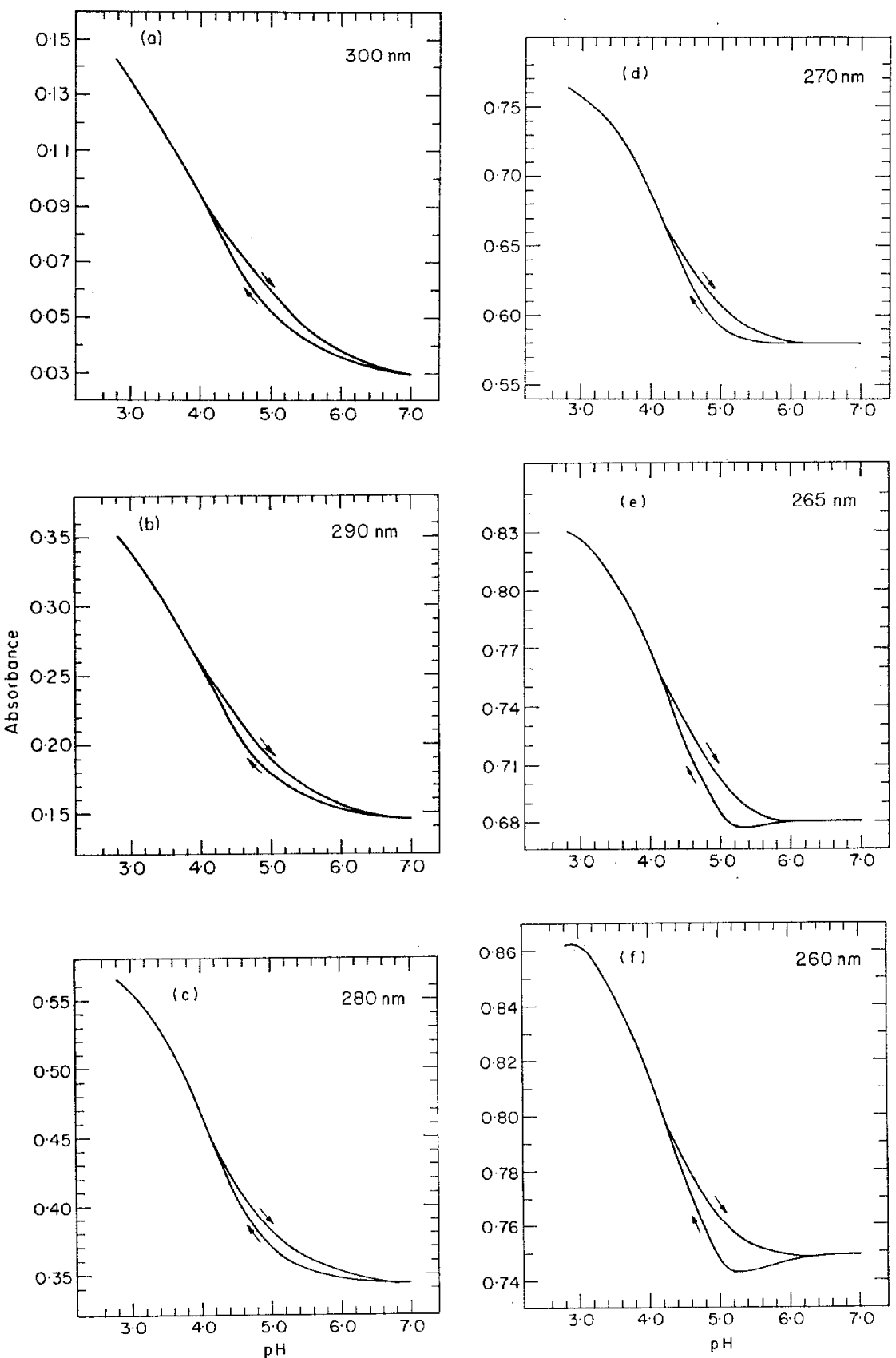

FrG. 3. Spectrophotometric titration of unfractionated $E$. coli rRNA. Experimental conditions: $T=20^{\circ} \mathrm{C}$; buffer, $0.009 \mathrm{M}$ - NaCl, $0.001 \mathrm{M}$-sodium cacodylate. These data were derived using RNA from either preparation, without addition of $\mathrm{Mg}^{2+}$ ions. All data have been converted to a standard RNA concentration of $10^{-4} \mathrm{M}-[\mathrm{P}]$. For each of the six wavelengths shown, the lower curve is the acid branch of the hystcrosis loop and the upper curve is the base branch from pH 2.8 . Curves are for time-independent absorbance readings (see text). 

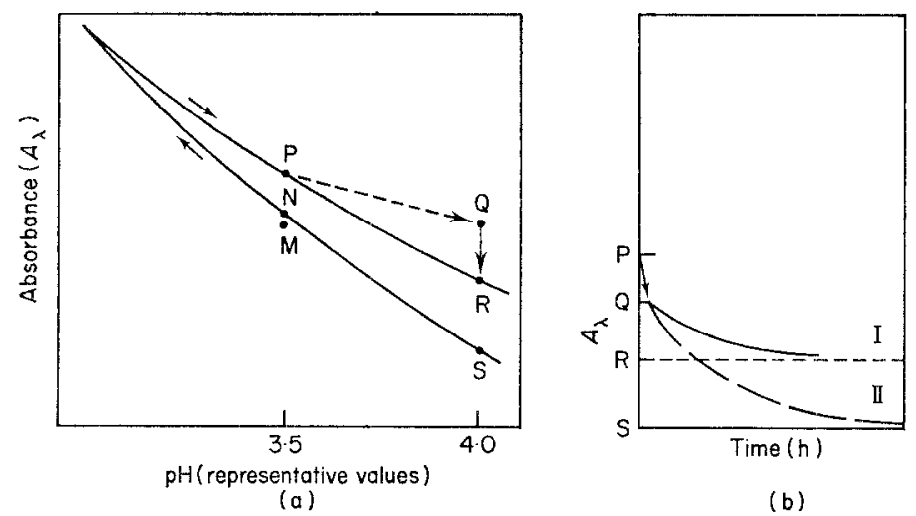

Fra. 4. Time-course of absorbance after a change in pH (schematic). See text for details.

resulting $\mathrm{pH}$ value is, say, $4 \cdot 0$. If we read the absorbance as soon as possible after adding the titrant, the $A_{\lambda}$ value will be that of point $Q$. The absorbance then falls to point $R$ over a period of several hours (the length of time depending on the actual $\mathrm{pH}$ and on the size of the $\mathrm{pH}$ change between points $\mathrm{P}$ and $\mathrm{R}$ ). The time-course of the absorbance change is shown in Figure $4(\mathrm{~b})$. With our experimental procedure we cannot follow the kinetics of the fast drop in absorbance from $\mathrm{P}$ to $\mathrm{Q}$. We can, however, monitor the levelling-off of the absorbance change to point $R$ (curve I, Fig. 4(b)). We shall consider below the nature of the reaction which results in the slow change in $A_{\lambda}$ from $\mathrm{Q}$ to $\mathrm{R}$.

The points from which Figure 2(a) to (f) were constructed are "levelled-off" values, and it is in this sense that the hysteresis loops are time independent. Leaving the solution for an additional 24 hours or more at point $R$ on the base branch does not result in significant further decrease of the absorbance. (It was not feasible to leave the solutions for weeks or months due to degradation by hydrolysis or from. any nucleases which may have slipped through despite our precautions (Cox, 1968).)

If we consider the addition of acid to a solution at point $S$ on the acid branch of the loop (Fig. 4(a)), we find similar temporal behavior. Our first $A_{\lambda}$ reading after adding the acid is at point $M$, and the absorbance slowly rises to a final value at point $\mathrm{N}$. The absorbance difference represented by points NM was found to be rather smaller than that represented by points $Q R$ (the value for NM was typically $\leq 0.005$ absorbance unit for $[\mathrm{P}]=10^{-4} \mathrm{M}$ ), and $A_{\lambda}$ levels off at $\mathrm{N}$ after one to two hours.

Although there are slow absorbance changes with time after addition of a portion. of titrant, the "time-independent" values (cf. $R, N$ ) are independent of the rate of titration used in reaching these values. Thus, the curves in Figure 2 were first derived from several very slow titrations; each $\mathrm{pH}$ change was 0.25 unit and no titrant was added until the absorbance change had levelled off ( 2 to $8 \mathrm{~h}$ at each $\mathrm{pH}$ value). Such long titrations were not very practical if, for instance, pairs of solutions were desired at the same $\mathrm{pH}$ value but on different branches of the loop. Therefore, experiments were performed in which solutions were titrated to low $\mathrm{pH}$ rather quickly (reading absorbance every $0.5 \mathrm{pH}$ unit and waiting only 5 to $10 \mathrm{~min}$ at each $\mathrm{pH}$ ) and were then titrated with base directly to the $\mathrm{pH}$ value of interest. When the slow absorbance changes at this $\mathrm{pH}$ ceased after some hours, it was found that the final absorbance 
readings were the same (within a small scatter) as those from the very slow titrations. Thus, any slow reactions which may be occurring at lower $\mathrm{pH}$ values do not affect the time-independent base branch of the hysteresis loop. It was likewise found that the time-independent values of absorbance for the acid branch also do not depend on the titration rate.

The situation at low ionic strength appears to be less complex, since any slow changes in absorbance following addition of acid or base were found to be quite small.

\section{(d) Dependence of hysteresis loops on ionic strength and ionic composition}

Most experiments were performed using solutions of RNA in $0 \cdot 1 \mathrm{M}-\mathrm{Na}^{+}$buffer, containing $0.099 \mathrm{M}-\mathrm{NaCl}$ and $0.001 \mathrm{M}$-sodium cacodylate. The absence of cacodylate had no effect on the titration curves. Some titrations were made using solutions of RNA in $0.1 \mathrm{M}-\mathrm{Na}^{+}$buffer to which either $\mathrm{Mg}^{2+}$ ions $\left(\sim 2 \times 10^{-4} \mathrm{M}\right)$ or EDTA $\left(\sim 5 \times 10^{-4} \mathrm{M}\right)$ had been added. These experiments yielded two very important results.

(1) The acid branch titration curves (at $I=0 \cdot 1 \mathrm{M}$ ) were found to be identical for experiments using buffers containing $\mathrm{NaCl}$ only, or to which $\mathrm{Mg}^{2+}$ ions or EDTA had been added. Thus, the presence or absence of $\mathrm{Mg}^{2+}$ ions does not appear to affect the changes in secondary structure which occur as the $\mathrm{pH}$ is lowered from $\mathrm{pH} 7$.

(2) In contrast, the base branch of the hysteresis cycle is markedly affected by $\mathrm{Mg}^{2+}$ ions. The complexing of divalent ions by EDTA eliminates the hysteresis. In solutions containing EDTA, we still observed slow changes in absorbance after the $\mathrm{pH}$ was raised by addition of base, but the "levelled-off" value of $A_{\lambda}$ coincided with the acid branch. This situation is illustrated by curve II of Figure $4(\mathrm{~b})$. After the $\mathrm{pH}$ was changed from, typically, $3 \cdot 5$ to $4 \cdot 0$, our first absorbance reading was, say, at point $\mathrm{Q}$. The value of $A_{\lambda}$ then decreased with time along curve II, eventually (after several hours) reaching a final, timeindependent value at point $S$, which lies on the acid branch of the hysteresis loop. (Note that curves I and II in Figure 4(b) are for illustrative purposes only-no quantitative significance should be attached to the relative rates of absorbance decrease shown in these curves.) Thus, the presence of $\mathrm{Mg}^{2+}$ ions seems to be necessary for formation and retention of at least some of the metastable conformations which rRNA may assume.

Support for these conclusions derives from the observation that addition of excess EDTA to a solution at $\mathrm{pH} 4$ on the acid branch results in no change in the (dilutioncorrected) absorbance. A slow decrease in $A_{\lambda}$ (over a 24-hour period) is seen for the corresponding base branch solution plus EDTA, with the levelled-off value being somewhat above the acid-branch value. This implies that EDTA can remove some, but not all, of the $\mathrm{Mg}^{2+}$ ions tightly bound to base-branch RNA.

Titrations in the presence of $\mathrm{Mg}^{2+}$ gave hysteresis loops as shown in Figure 2. In the absence of either additional $\mathrm{Mg}^{2+}$ or EDTA, loops identical to those in Figure 2 were found upon titration of our first RNA preparation, while smaller loops were obtained using a second preparation of RNA. We conclude that the first RNA batch may have contained enough residual $\mathrm{Mg}^{2+}$ to give the full loops, while the second preparation had a lower level of residual $\mathrm{Mg}^{2+}$. 


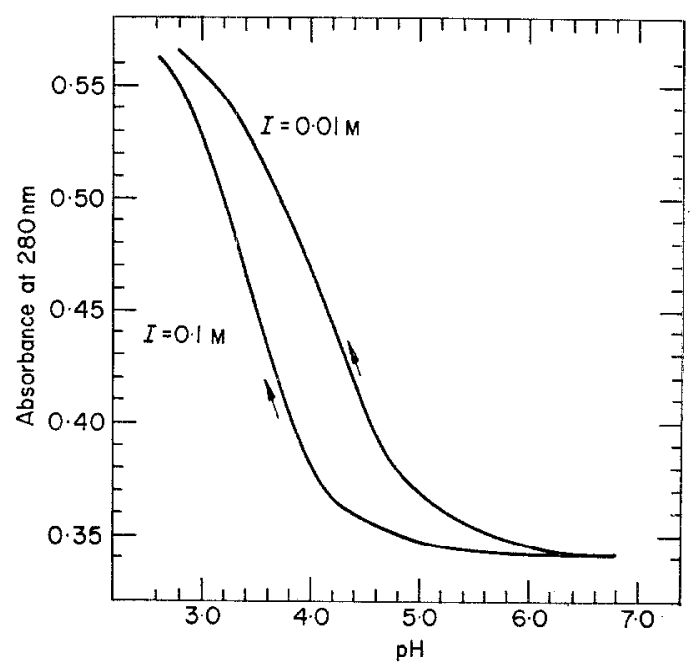

Frg. 5. Comparison of acid-branch titration curves at $T=20^{\circ} \mathrm{C}$ for solutions of different ionic strength. Data were converted to the standard RNA eoncentration of $10^{-4} \mathrm{M}-[\mathrm{P}]$.

A decrease in ionic strength to $0.01 \mathrm{~m}(0.009 \mathrm{M}-\mathrm{NaCl}, 0.001 \mathrm{M}$-sodium cacodylate) has a marked effect. Comparing the acid titration curves at $\lambda=280 \mathrm{~nm}$ for $I=0 \cdot 1 \mathrm{M}$ and $I=0.01 \mathrm{M}$ solutions (Fig. 5) we see that, as expected, the higher salt concentration retards the opening of the RNA structure, which occurs at much higher $\mathrm{pH}$ values in the $I=0.01 \mathrm{~m}$ solution (Cox \& Littauer, 1963). Furthermore, the hysteresis virtually disappears at low ionic strength (Fig. 3). It is found that the titration curve is rapidly reversible between $\mathrm{pH} 2.8$ and $\mathrm{pH} 4$. That is, in this $\mathrm{pH}$ range our first $A_{\lambda}$ reading after addition of base was coincident with the acid-branch curve, and we observed no further decrease in absorbanoe with timo. Therc does appear to be a small hysteresis as shown in Figure 3. It should be noted that the ionic strength increases during the titration cycle due to addition of titrant, as well as from diffusion of $\mathrm{KCl}$ from the reference electrode tip. This last effect can be quite importantwhen, as a test, we left the electrode in $\mathrm{pH} 7$ RNA solution for two days before commencing the titration, a curve was obtained intermediate to those shown in Figure 5. The results in Figure 3 are from fairly rapid titration experiments (cycle time about 3 hours). In any case, we see that the hysteresis becomes less pronounced at lower ionic strength.

\section{(e) Intramolecular nature of hysteresis}

Direct evidence that the hysteresis phenomenon reflects intramolecular conformational rearrangements is provided by ultracentrifuge measurements. Sedimentation coefficients measured at several $\mathrm{pH}$ values (Revzin et al., manuscript in preparation) do not show large variation with $\mathrm{pH}$ down to about $\mathrm{pH} 3$, and certainly do not indicate even aggregation to dimers. Additional evidence against aggregation is derived from analysis of the sedimentation boundaries. At each $\mathrm{pH}$ value, a welldefined two-peak system was observed, as expected for our $16 \mathrm{~S}$ and $23 \mathrm{~S}$ mixture of rRNA. 
As a further check, solutions were prepared at $\mathrm{pH} 3.7$ on the acid and base branches (at $I=0.1 \mathrm{~m}$ ), and a sedimentation run was performed on both solutions simultaneously. The results are shown in Table 1.

TABLE 1

Sedimentation coefficients at $p H 3 \cdot 7$

\begin{tabular}{lll}
\hline Solution & $s_{\text {fast }}$ & $s_{\text {slow }}$ \\
\hline Acid branch & $20.5 \mathrm{~S}$ & $15.5 \mathrm{~S}$ \\
Base branch & $21.5 \mathrm{~S}$ & $16.5 \mathrm{~S}$ \\
\hline
\end{tabular}

RNA concentration $-10^{-4} \mathrm{Mr}-[\mathrm{P}], T=20^{\circ} \mathrm{C}, I=0.1 \mathrm{M}$.

Each solution showed a two-peak sedimentation boundary. The $s$-values for the base-branch are seen to be slightly larger than those for the acid-branch solution. This similarity in $s$ values for the two branches appears to exclude the possibility that appreciable intermolecular association is involved in the hysteresis effects.

Titration experiments at different RNA concentrations can also give information about any possible aggregation. Our experimental set-up did not permit variation of the nucleotide concentration over a wide range, but spectrophotometric results from solutions differing in $[\mathrm{P}]$ concentration by a factor of two gave identical titration curves (after conversion of the data to the "standard concentration", $10^{-4} \mathrm{M}-[\mathrm{P}]$, Fig. 2). It is also worth noting that hysteresis is observed both optically and potentiometrically, although the RNA concentration in the absorbance experiments is lower by a factor of 40 .

Absorbance readings at $\lambda=340 \mathrm{~nm}$ were taken for each $\mathrm{pH}$ value in the spectrophotometric titrations. RNA shows virtually no absorbance at this wavelength, so changes in $A_{34.0}$ can be attributed to scattering from large aggregates which might possibly form. The value of $A_{340}$ was less than 0.005 unit and was invariant over the entire $\mathrm{pH}$ range, indicating the absence of large aggregated particles. We also measured $A_{340}$ as a function of $\mathrm{pH}$ for an RNA solution having $[\mathrm{P}]=4 \times 10^{-3} \mathrm{M}$ (comparable to the concentrations used in proton-binding experiments). The value of $A_{340}$ was unaffected by titration to $\mathrm{pH} 3$. No change was observed even after 12 hours, nor was any precipitate seen visually in this experiment or at any time during any of the potontiomotrio titrations. In summary, then, we may seek an explanation for the hysteresis phenomenon in terms of the presence of metastable secondary structures in single rRNA molecules.

\section{(f) Hysteresis cycles at $30^{\circ} \mathrm{C}$ and at $35^{\circ} \mathrm{C}$}

Slow optical titrations were performcd at $30^{\circ} \mathrm{C}$ and at $35^{\circ} \mathrm{C}$, in which owoh ohango in $\mathrm{pH}$ was 0.25 unit and no acid or base was added until the absorbance changes occurring after the previous addition of titrant had levelled off. The time-independent hysteresis loops were found to be similar to those at $20^{\circ} \mathrm{C}$, as given in Figure 2. (The higher temperature loops are translated to higher $\mathrm{pH}$ by $<0.5 \mathrm{pH}$ unit.) Thus, the higher temperatures used apparently do not markedly affect the formation of those 
structures upon which the hysteresis is based. The rates of the slow absorbance changes on the base branch increase with higher temperature, with levelling off completed in one to two hours.

\section{(g) Kinetics of the slow processes occurring after addition of titrant}

The kinetics of the slow processes on both the acid and base branches were followed by reading the absorbance at various times during the levelling off period (cf. curve I, Fig. 4(b)). The small total changes in $A_{\lambda}$ for points on the acid branch did not allow quantitative analysis of the rates. The effects were larger for the base branch and thus were more amenable to analysis. It seemed most likely that the slow changes on the base-branch result from "annealing" (by slippage) of mismatched base-paired regions to more stable configurations. Annealing reactions with half-lives of up to several days (at room temperature) have becn obsorved for long-chain synthetic polynucleotides (Blake \& Fresco, 1966; M. Spodheim, unpublished data) and for d(A-T) oligomers (Scheffler et al., 1968; Baldwin, 1968).

A single annealing process should follow an apparent first-order rate law. The experimental quantities are the absorbance readings at times zero $\left(A_{0}\right), t\left(A_{t}\right)$, and infinity (levelled-off value, $\left.A_{\infty}\right)$; thus a plot of $\log \left[\left(A_{t}-A_{\infty}\right)\right] /\left[\left(A_{0}-A_{\infty}\right)\right]$ versus $t$ should give a straight line having slope $-(2 \cdot 3 \tau)^{-1}$, where $\tau$ is the relaxation time for the process.

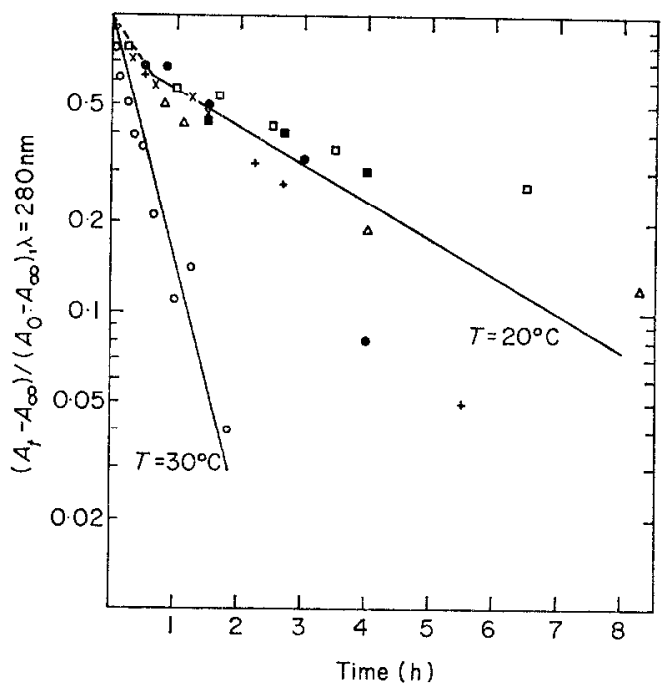

FIG. 6. Evaluation of kinetic data at $\mathrm{pH} 4.25$ for slow absorbance changes on the base branch $(I=0 \cdot 1$ м solution), see text. Symbols $(\square),(\square),(\times),(+),(\bullet),(\triangle)$ are for experiments at $T=20^{\circ} \mathrm{C}$; symbol $(O)$ is for $T=30^{\circ} \mathrm{C}$. For all data shown, the $\mathrm{pH}$ had been increased from $\mathrm{pH} 3.5$ to $\mathrm{pH} 4.25$, at which $\mathrm{pH}$ the absorbance changes were recorded as functions of time.

Figure 6 is such a graph for data at $\mathrm{pH} 4 \cdot 25, I=0 \cdot 1 \mathrm{M}$. It can be seen that straight lines are found within the scatter of the data. Although the scatter is large enough to preclude detailed consideration of other reaction orders, the data do imply that the slow process, on average, follows a first-order kinetic law. Using Figure 6 , then, we find $\tau_{1}{ }^{-1} \simeq 0.3 \mathrm{~h}^{-1}$ at $20^{\circ} \mathrm{C}$, and $\tau_{2}^{-1} \simeq 1.9 \mathrm{~h}^{-1}$ at $30^{\circ} \mathrm{C}$. The slippage mechanism 
probably requires that an entire sequence of base pairs open up before annealing to a more stable structure can occur. The value of $\tau^{-1}$ should primarily reflect the rate of this slow dissociation step. Thus, we may write $\tau^{-1}=k_{\mathrm{d}}$, where $k_{\mathrm{d}}$ denotes the average apparent rate constant for the dissociation. In such a case, we may use the change in relaxation time with temperature to estimate the average activation energy, $E_{\mathrm{a}}$, for the dissociation process, and we find $E_{\mathrm{a}} \simeq 32 \mathrm{kcal} / \mathrm{mol}$.

These rough values for $\tau^{-1}$ and $E_{\mathrm{a}}$ indicate the magnitudes of the quantities involved. The long relaxation times and rather high activation energy imply that the process under consideration involves a large number of elementary steps. The kinetic data for other $\mathrm{pH}$ values generally gave similar results, although in some cases relaxation times at $20^{\circ} \mathrm{C}$ and at $30^{\circ} \mathrm{C}$ were more nearly equal, indicating a lower activation energy at these $\mathrm{pH}$ values. We cannot predict a priori the changes in $\tau^{-1}$ and $E_{\mathrm{a}}$ with $\mathrm{pH}$ or temperature, since the exact reaction mechanism and the average stability for all mismatched regions may vary with $\mathrm{pH}$. A more complete kinetic study could reveal details about these mismatched "short-lived" metastable states that can form at acidic $\mathrm{pH}$ values. For the time being we note that our kinetic data are consistent with the interpretation that the slow process observed on the base branch is an annealing by slippage reaction.

\section{(h) Absorbance difference spectra at $80^{\circ} \mathrm{C}$}

Solutions at the same $\mathrm{pH}$ but on different branches of the hysteresis loop were heated to 75 to $85^{\circ} \mathrm{C}$. We wished to observe whether the metastable structures that are present at $20^{\circ} \mathrm{C}$ break down at higher temperatures, with both solutions then reverting to the "equilibrium" state upon cooling. If, on the other hand, some metastable conformations persist at $80^{\circ} \mathrm{C}$, we may use the spectral differences between the acid and base-branch solutions (at $80^{\circ} \mathrm{C}$ ) to deduce the nature of the metastable structures themselves.

We find that heating to $80^{\circ} \mathrm{C}$ does not destroy the metastable conformations in $\mathrm{Mg}^{2+}$-containing solutions; the differences between the acid and base branches are reproduced at all $\lambda$ after the solutions are cooled back to $20^{\circ} \mathrm{C}$. Heating to $80^{\circ} \mathrm{C}$ does seem to cause some hydrolytic degradation of the RNA, but the small absorbance increase accompanying the hydrolysis is very nearly the same for both branches. In some experiments the spectral differences at $20^{\circ} \mathrm{C}$ before and after heating were similar but not quito idontioal. This may be duo to somo exporimontal uncertainties or to breakdown of a fairly small fraction of the metastable states at high temperature. In general, however, we conclude that heating to $80^{\circ} \mathrm{C}$ in the presence of $\mathrm{Mg}^{2+}$ ions does not cause the system to overcome the high energy barrier that gives rise to the long-lived metastability. On the other hand, heating of acid and base-branch solutions to which excess EDTA was added gave equal absorbance values at $60^{\circ} \mathrm{C}$ and at $80^{\circ} \mathrm{C}$, and furthermore the absorbance spectra remained coincident after cooling to $20^{\circ} \mathrm{C}$.

Spectral differences at $20^{\circ} \mathrm{C}$ between iso- $\mathrm{pH}$ solutions on the two branches of the hysteresis loop are due not only to the specific structures that are responsible for the metastability, but also include contributions from other structures (cf. A.U and $G \cdot C$ base pairs) which may be prevented from forming (or are induced to form) because of the presence of the metastable conformations. The same problem exists when comparing spectra at high temperature, but to a much lesser extent since at $80^{\circ} \mathrm{C}$ most 


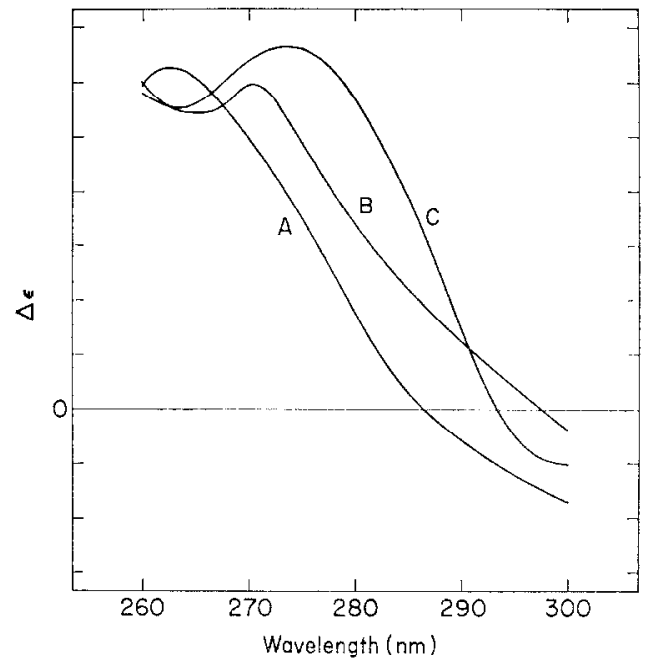

Fra. 7. Absorbance difference spectra (in arbitrary units) at $T=80^{\circ} \mathrm{C}$, for iso-pH solutions on the two branches of the hysteresis loop. Curve $\mathrm{A}, \mathrm{pH} 4 \cdot 0$; curve $\mathrm{B}, \mathrm{pH} 3 \cdot 7$. In both cases, at $80^{\circ} \mathrm{C}$ the absorbanee of the base-branoh solution is lower than that of the acid-branch solution. Curve $\mathrm{C}$ represents absorbance changes upon formation of $G \cdot G$ helical structures (Pochon \& Michelson, 1965). Protonation of G.G base pairs will have little effect on the shape of curve $\mathrm{C}$ (Beaven et $a l ., 1955)$. If curve $\mathrm{C}$ is modified to include spectral changes accompanying $\mathrm{A} \cdot \mathrm{A}$ formation (Revzin et $a l$., manuscript in preparation) the resulting curve will more closely resemble the experimental curves $\mathrm{A}$ and $\mathrm{B}$.

of the extraneous structures have melted out (Stanley \& Bock, 1965; Cox, 1966). The major part of the difference spectrum at $80^{\circ} \mathrm{C}$ may thus arise from the metastable structure itself. Accordingly, we have evalualed the difference spectra at $80^{\circ} \mathrm{C}$ for solutions at $\mathrm{pH} 3.7$ and at $\mathrm{pH} 4.0$ (Fig. 7). We wish first to emphasize the result that, while at $20^{\circ} \mathrm{C}$ the absorbance on the base branch is higher (indicating less structure than on the acid branch), this situation is reversed at elevated temperature, where we find that there is a lower absorbance (and hence more structure) for the base branch. We see from curves $A$ and $B$ in Figure 7 that difference spectra at both $\mathrm{pH}$ values have the same general shape. Comparison of curves $\mathrm{A}$ and $\mathrm{B}$ in Figure 7 with spectra for various conceivable metastable conformations shows that spectral differences at $80^{\circ} \mathrm{C}$ are consistent with the presence of protonated $\mathrm{G} \cdot \mathrm{G}$ structures in RNA on the base branch (curve C of Fig. 7) (Beaven et al., 1955; Pochon \& Michelson, 1965). It is of further interest that the presence of protonated $A \cdot A$ base pairs in addition to $G \cdot G$ pairs in the metastable conformation could shift the predicted curve $\mathrm{C}$ into closer agreement with the experimental results curve $\mathrm{A}$ and curve $\mathrm{B}$ (Revzin et al., manuscript in preparation).

\section{(i) Titration of transfer $R N A$}

Spectrophotometric titration of a preparation of unfractionated $E$. coli tRNAs showed no time-independent hysteresis loops (Fig. 8). Slow changes in absorbance with time following addition of acid were very small or non-existent. However, slow changes with time were noted upon titration with base. These changes, which as in rRNA are presumably due to annealing of mismatched regions, appeared to level off after about one hour, with the final (dilution corrected) absorbance value bcing the 


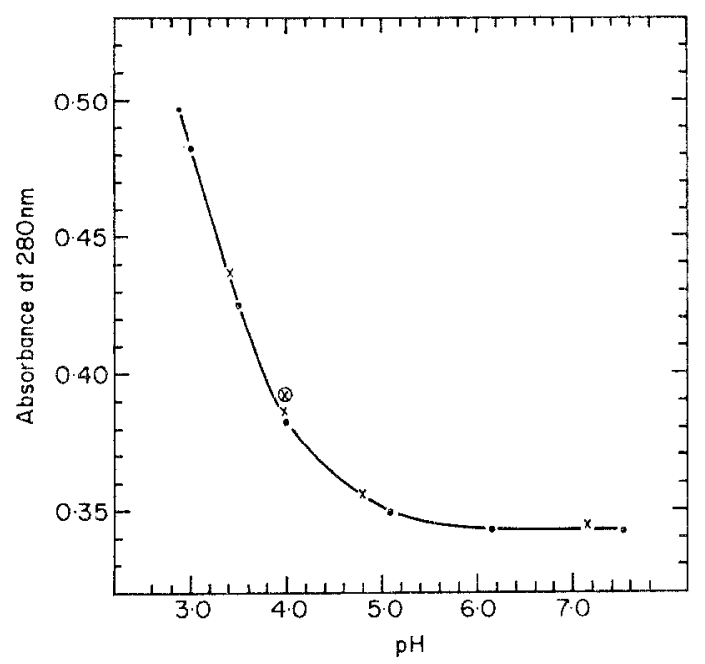

FIG. 8. Spectrophotometric titration of unfractionated E. coli tRNA. Experimental conditions: $T=20^{\circ} \mathrm{C}$; buffer, $0.099 \mathrm{M}-\mathrm{NaCl}, 0.001 \mathrm{M}$-sodium cacodylate, $\sim 2 \times 10^{-4} \mathrm{Mr}^{-\mathrm{MgCl}_{2}}$; tRNA concentration, $\sim 10^{-4} \mathrm{M}$-[P]. Symbols (O) are time-independent values upon titration with acid from $\mathrm{pH} 7$, symbols $(X)$ are time-independent values upon titration with base from $\mathrm{pH} 2 \cdot 8$. At $\mathrm{pH} 4,(\otimes)$ is the first absorbance reading following the $\mathrm{pH}$ change from $\mathrm{pH} 3 \cdot 4$, while $(x)$ is the levelled-off reading coincident with the acid branch.

same as that on the acid branch. Thus, a tRNA mixture can pass through "shortlived" metastable conformational states, but does not show a long-lived hysteresis phenomenon as does ribosomal RNA.

\section{Discussion}

(a) Events that occur during the RNA titration cycle

We note again our assumption that the $\mathrm{pH} 7$ structure corresponds to the generally accepted model for rRNA; namely, that the molecule is composed of a series of doublehelical regions (stabilized primarily by Watson-Crick hase pairs) connected by singlestranded lengths of unpaired bases. As the $\mathrm{pH}$ of an RNA solution of $0.1 \mathrm{M}$ ionic strength is lowered, a number of reactions occur, including the protonation of $\mathrm{A}, \mathrm{C}$ and $G$ residues, along with the opening of $A \cdot U$ and $G \cdot C$ buse puirs (Cox \& Littauer, 1963). A detailed analysis of absorbance and proton-binding data (Revzin et al., manuscript in preparation) implies that in addition to the above-mentioned processes some other reactions also take place. One of these reactions may be the formation of a protonated three-stranded $\mathrm{G} \cdot \mathrm{C} \cdot \mathrm{G}$ structure in the region $3 \cdot 8<\mathrm{pH}<\mathbf{6 \cdot 0}$. This structure disappears at lower $\mathrm{pH}$, and conformations consisting of sequences rich in $\mathrm{G} \cdot \mathrm{G}$ and $\mathrm{A} \cdot \mathrm{A}$ double helices may be formed. We believe that the "high $\mathrm{pH}$ " structure is not very important for the hysteresis, but that the second class of structures is crucial. The extent of "low $\mathrm{pH}$ " structure formation increases as the $\mathrm{pH}$ approaches pH 2.6. Upon addition of base, the acid-stable regions are eventually transformed to the various structures which are present at higher $\mathrm{pH}$, but these reverse processes set in at $\mathrm{pH}$ values considerably above those at which the forward reactions take place. This, of course, is merely a statement that hysteresis is displayed by the system. 


\section{(b) The acid branch of the hysteresis cycle is an equilibrium curve}

In general, both branches of a hysteresis cycle can represent metastable states of the system-the true equilibrium curve would then lie somewhere within the loop (Everett, 1967). For RNA, the titrations in EDTA solution show that in the absence of $\mathrm{Mg}^{2+}$ the system does not display hysteresis. Rather the same time-independent curve is followed whether the $\mathrm{pH}$ is being decreased or increased, and this curve coincides with the acid branch of the hysteresis loop in $\mathrm{Mg}^{2+}$ solution. Removal of $\mathrm{Mg}^{2+}$ ions from the base-branch solution using EDTA (plus heat) also causes the system to relax to the acid-branch curve. Thus, the acid branch is the equilibrium curve and the metastable states (in $\mathrm{Mg}^{2+}$ solution) occur along the base branch. The changes in secondary structure that occur upon titration with acid are apparently identical in the presence or absence of $\mathrm{Mg}^{2+}$. Therefore, the non-equilibrium structure is most probably an acid-stable conformation (either $G \cdot C \cdot G$ or $(G \cdot G, A \cdot A)$ ) which is "frozen" by $\mathrm{Mg}^{2+}$ ions into a metastable state.

The proposed triple-helical structure begins to form at about $\mathrm{pH} 6$, yet the hysteresis is seen only if the $\mathrm{pH}$ has been decreased below $\mathrm{pH} 3.8$. Thus the high $\mathrm{pH}$ structure does not appear to be responsible for the metastability. In general, it is assumed that a metastable state is prevented from transforming to the equilibrium state (of lower free energy) by the presence of a large energy barrier. It seems unlikely that such an energy barrier would suddenly develop in the high $\mathrm{pH}$ structure as the $\mathrm{pH}$ is lowered below pHI $3 \cdot 8$.

\section{(c) Metastable guanine -guanine structures may underlie the hysteresis}

A number of observations has led us to conclude that $G \cdot G$ structures are present in metastable conformation on the base branch of the cycle. The absorbance difference spectra at $80^{\circ} \mathrm{C}$ for iso-pH RNA solutions at $\mathrm{pH} 3.7$ and at $\mathrm{pH} 4.0$ are consistent with the presence of $G \cdot G$ rich sequences in RNA on the base branch even though we predict that such sequences are not present at these $\mathrm{pH}$ values on the acid branch. Thus, $G \cdot G$ rich regions which form only at lower $\mathrm{pH}$ on the acid branch appear to persist to higher $\mathrm{pH}$ values on the base branch. The high stability of $\mathrm{G} \cdot \mathrm{G}$ structures is well known (for review see Michelson et al., 1967; Fresco \& Massoulié, 1963; Pochon $\&$ Michelson, 1965). For example, to prepare poly $(\mathrm{G}) \cdot \operatorname{poly}(\mathrm{C})$ by mixing poly $(\mathrm{G})$ and poly $(\mathrm{C})$, it is necessary to heat the solution to at least $80^{\circ} \mathrm{C}$ (in $8 \mathrm{M}$-urea) (Englunder et al., 1972). Thus, even in the presence of the poly $(\mathrm{C})$, which creates a large driving force for formation of the very stable $\operatorname{poly}(G) \cdot \operatorname{poly}(C)$ structure, $\operatorname{poly}(G)$ persists in metastable, self-associated conformations to rather high temperatures. Guanine residues can aggregate into a number of structures, involving several possible base pairing schemes (Gellert et al., 1962; Pochon \& Michelson, 1965; Chantot et al., 1971). One can devise $G \cdot G$ base pairs in which protons participate in $H$ bonding and are thus essential for the $G \cdot G$ formation. One can also propose $G \cdot G$ pairings in which protons moroly holp to stabilize the structure by partially compensating the electrostatic repulsion between the negatively charged phosphate backbones. The strands of $G \cdot G$ helices might be parallel or antiparallel. We conclude, therefore, that the versatility of $\mathrm{G}$ residues in forming helical structures, some (or all) of which are known to show metastability, coupled with our prediction that $G \cdot G$ is formed at low $\mathrm{pH}$ on the acid branch (Revzin et al., manuscript in preparation) and with the difference spectra at 
$80^{\circ} \mathrm{C}$ provides strong support for our contention that $\mathrm{G} \cdot \mathrm{G}$ regions have an important role in causing the hysteresis.

We have observed that $\mathbf{M g}^{2+}$ ions cun convert a structure that is not metastable in the presence of EDTA into a metastable conformation. Similar marked effects of $\mathrm{Mg}^{2+}$ ions are well known from other studies of polynucleotides. For example, a 1:1 mixture of poly(A) and poly $(\mathrm{U})\left([\mathrm{P}] \sim 10^{-4} \mathrm{M}\right)$ in $\mathrm{NaCl}$ solution will form a complex only when the $\mathrm{Na}^{+}$ion concentration is at least $10^{-2} \mathrm{M}$. In $\mathrm{MgCl}_{2}$ solution, however, the complex will form when the $\mathrm{Mg}^{2+}$ ion concentration is only $10^{-4} \mathrm{M}-$ a factor of 100 lower than for the solution of monovalent cations (Felsenfeld \& Rich, 1957). Even more relevant to our study is the finding of Fresco and co-workers (Lindahl et al., 1966; Adams et al., 1967) that certain tRNAs can exist in more than one form at room temperature, depending on whether $\mathrm{Mg}^{2+}$ ions are present in the system. In one such "denaturable" tRNA system, interconversion between the two forms is achieved by heating to $60^{\circ} \mathrm{C}$ in the presence of $\mathrm{Mg}^{2+}$ (Lindahl et al., 1966). Our hysteresis results give further evidence that $\mathrm{Mg}^{2+}$ ions can have a unique role in stabilizing multi-stranded polynnclentide conformations.

It is observed experimentally that there is little or no hysteresis in solutions of $0.01 \mathrm{M}$ ionic strength. We have concluded from our quantitative analysis of absorbance data (Revzin et al., manuscript in preparation) that no triple-helices are formed at $I=0.01 \mathrm{M}$, but that $\mathrm{G} \cdot \mathrm{G}$ and $\mathrm{A} \cdot \mathrm{A}$ rich regions begin to form even at rather high $\mathrm{pH}$ values. This might be taken as indirect evidence that a metastable $G \cdot C \cdot G$ structure is involved in the $I=0.1 \mathrm{~m}$ hysteresis. A more likely possibility, however, is that at lower ionic strength the increased electrostatic repulsion between the phosphate backbones prevents the triple helix from forming and also removes the metastability from the $G \cdot G$ regions so that these form and dissociate reasonably rapidly. Low ionic strength is known to stabilize some protonated polynucleotide structures, such as $\mathrm{A} \cdot \mathrm{A}$ and $\mathrm{C} \cdot \mathrm{C}$ (see Michelson et al., 1967, p. 102). However, even though the proposed $G \cdot C \cdot G$ and $G \cdot G$ structures will involve protonated bases at low $\mathrm{pH}$ values, a decrease in ionic strength will stabilize such structures only if the proton provides a net attractive force for the phosphate- $\mathrm{H}^{+}-$phosphate system. We have no evidence that this need be the case for our proposed helical regions, which could well be destabilized at lower ionic strengths.

We have presented evidence that $G \cdot G$ along with $A \cdot A$ base pairs may be involved in metastable structures during the titration cycle of ribosomal RNA. In sequencing $E$. coli rRNA, Fellner and his associates have found certain rather long sequences (up to 17 residues) containing only $G$ and $A$, except for one or two pyrimidine residues (Fellner et al., 1972a,b; Ehresmann et al., 1972). Furthermore, there are several homologous sequences rich in $\mathrm{G}$ and $\mathrm{A}$ residues. Should two such sequences match up during titration, they could be very stable, since any A-A base pairs would help stabilize the structure, especially if the strands are parallel. Our tRNA titrations imply that the sequences that underlie the hysteresis in rRNA may be rather long ones. The mixture of tRNAs should approximate a ribosomal RNA in that the double-helical regions present at $\mathrm{pH} 7$ will vary in base composition from mostly $A \cdot U$ to mostly $G \cdot C$, although the tRNAs sequenced to date seem to have helical regions of limited length (4 to 7 base pairs). There are apparently few long stretches of (A,G) residues (Zachau, 1969). Thus, the absence of hysteresis in the titration of unfractionated $E$. coli tRNA is indirect evidence that long purine stretches may underlie the longlived metastability in rRNA. 
The presence of metastable $\mathrm{G} \cdot \mathrm{G}$ structures at $\mathrm{pH}<\mathbf{3 \cdot 8}$ is sufficient to account for the scanning curves from both branches of the cycle. The series of scanning curves obtained from the acid branch may simply reflect the formation of more $G \cdot G$ regions at lower $\mathrm{pH}$ values as additional $\mathrm{G}$ residues become available after the opening of $A \cdot U$ and $G \cdot C$ base pairs. These $G \cdot G$ regions break down only at a $p H$ higher than the $\mathrm{pH}$ at which they are formed. However, once they do open up they are not reformed until lower $\mathrm{pH}$ values; thus we have scanning from the base branch as well.

\section{(d) Biological implications of metastable structures}

Hysteresis phenomena that are familiar from physics, such as magnetic and ferroelectric hysteresis, are based on interactions among "domains" of polycrystalline systems (Everett, 1967). Ribosomal RNA presents an analogous situation, except that the "domains" are part of the same molecule. We can ask whether metastable conformational states in individual molecules may have a biological role. Katchalsky and co-workers (Katchalsky \& Oplatka, 1966; Katchalsky \& Neumann, 1972) have considered some aspects of this question.

We wish first to emphasize the importance of the time scale on which the lifetime of the metastability is considered. In general, time-independent hysteresis loops are taken to mean loops that do not change for days, weeks or months. For biological systems, such long lifetimes are probably not necessary, since a metastable structure that exists for several hours should be able to fulfil its designated function. Thus, the metastable conformations on the base branch of the rRNA hysteresis loop (or perhaps even the "short-lived" metastable states of the base branch which anneal out after hours) are probably "time independent" on a metabolic time scale.

We have studied ribosomal RNA, but, unfortunately, the mechanisms of ribosome function are so little understood that we can only state generalities such as "metastable conformations of ribosomes could affect protein synthesis". It is worthy of note that Fukami \& Imahori (1971) have induced metastable states in R17 viral RNA used as a messenger RNA, and have observed different rates of protein synthesis for the native and denatured forms. Likewise, it has been speculated that the denaturable tRNAs discovered by Fresco et al. (1966) and by Gartland \& Sueoka (1966) could also have a role in the protein synthesis control mechanism. An important feature of the metastable state is that, should such a structure be generated during a singular cellular event (e.g. a nerve impulse or a sudden ion flux), it will remain in the metastable conformation even though the environment has returned to "normal" after the event. Thus, metastable states may influence biological procosses long after the initial trigger signal has passed.

\section{Conclusion}

The existence of hysteresis in the titration behaviour of $E$. coli rRNA has led us to delve into the structures and the kinetic barriers that exist in ribosomal RNA molecules at the various stages of the titration cycle. We propose that metastable $G \cdot G$ structures are involved in the hysteresis phenomenon. We conclude that the possibility of metastable conformations involving $G$ residues may be worth considering when examining the properties of all natural RNAs which display marked secondary structure. 
We are grateful to Dr D. Elson and Dr U. Z. Littauer for generous gifts of RNA samples. We wish to thank Dr N. R. Kallenbach for comments on the manuscript. This work was supported, in part, by a National Science Foundation postdoctoral fellowship granted to one of us (A. R.) and by a grant from the Stiftung Volkswagenwerk to a second author (E. N.).

\section{REFERENCES}

Adams, A., Lindahl, T. \& Fresco, J. R. (1967). Proc. Nat. Acad. Sci., U.S.A. 57, 16841691 .

Arnott, S., Hutchinson, F., Spencer, M., Wilkins, M. H. F., Fuller, W. \& Langridge, R. (1966). Nature (London), 211, 227-232.

Baldwin, R. L. (1968). In Molecular Associations in Biology (Pullman, B., ed.), pp. 145162, Academic Press, New York.

Beaven, G. H., Holiday, E. R. \& Johnson, E. A. (1955). In The Nucleic Acids (Chargaff, E. \& Davidson, J. N., eds), vol. 1, pp. 493-553, Academic Press, New York.

Blake, R. D. \& Fresco, J. R. (1966). J. Mol. Biol. 19, 145-160.

Chantot, J. F., Sarocchi, M. Th. \& Guschlbauer, W. (1971). Biochimie, 53, 347-354.

Cox, R. A. (1966). Biochem. J. 98, 841-857.

Cox, R. A. (1968). Quart. Rev. Chem. Soc. 22, 499-526.

Cox, R. A. \& Katchalsky, A. (1972). Biochem. J. 126, $1039-1054$.

Cox, R. A. \& Littauer, U. Z. (1963). Biochim. Biophys. Acta, 72, 188-202.

Doty, P., Boedtker, H., Fresco, J. R., Haselkorn, R. \& Litt, M. (1959). Proc. Nat. Acad. Sei., U.S.A. 45, 482-499.

Ehresmann, C., Stiegler, P., Fellner, P. \& Ebel, J.-P. (1972). Biochimie, 54, 901-967.

Eilam, Y. \& Elson, D. (1971). Biochemistry, 10, 1489-1495.

Englander, J. J., Kallenbach, N. R. \& Englander, S. W. (1972). J. Mol. Biol. 63, 153-169.

Everett, D. H. (1967). In The Solid-Gas Interface (Flood, E. A., ed.), vol. 2, pp. 1055-1113, Marcel Dekker, New York.

Fellner, P., Ehresmann, C. \& Ebel, J.-P. (1972a). Biochimie, 54, 853-900.

Fellner, P., Ehresmann, C., Stiegler, P. \& Ebel, J.-P. (1972b). Nature New Biol. 239, 1-5.

Felsenfeld, G. \& Rich, A. (1957). Biochim. Biophys. Acta, 26, 457-468.

Fresco, J. R. \& Massoulié, J. (1963). J. Amer. Chem. Soc. 85, 1352-1353.

Fresco, J. R., Adams, A., Ascione, R., Henley, D. \& Lindahl, 'T. (1966). Cold Spring Harbor Symp. Quant. Biol. 31, 527-537.

Fukami, H. \& Imahori, K. (1971). Proc. Nat. Acad. Sci., U.S.A. 68, 570-573.

Gartland, W. J. \& Sueoka, N. (1966). Proc. Nat. Acad. Sci., U.S.A. 55, 948-956.

Gellert, M., Lipsett, M. N. \& Davies, D. R. (1962). Proc. Nat. Acad. Sci., U.S.A. 48, 2013-2018.

Katchalsky, A. \& Neumann, E. (1972). Intern. J. Neuroscience, 3, 175-182.

Katchalsky, A. \& Oplatka, A. (1966). Neurosciences Res. Symp. Sum. 1, 352-374.

Lindahl, T., Adams, A. \& Fresco, J. R. (1966). Proc. Nat. Acad.Sci., U.S.A. 55, 941-948.

Littauer, U. Z. \& Eisenberg, H. (1959). Biochim. Biophys. Acta, 32, 320-337.

Michelson, A. M., Massoulié, J. \& Guschlbauer, W. (1967). Progr. Nucl. Acid Res. Mol. Biol. 6, 83-141.

Pochon, F. \& Michelson, A. M. (1965). Proc. Nat. Acad. Sci., U.S.A. 53, 1425-1430.

Scheffler, I. E., Elson, E. L. \& Baldwin, R. L. (1968). J. Mol. Biol. 36, 291-304.

Spirin, A. S. \& Gavrilova, L. P. (1969). The Ribosome, Springer-Verlag, Berlin.

Spitnik-Elson, P. \& Atsmon, A. (1969). .T. Mol. Biol. 45, $113-124$.

Stanley, W. M., Jr. \& Bock, R. M. (1965). Biochemistry, 4, 1302-1311.

Steinhardt, J. \& Beychock, S. (1964). In The Proteins (Neurath, H., ed.), vol. 2, 2nd edit., pp. 139-304, Academic Press, New York.

Tanford, C. (1962). Advan. Protein Chem. 17, 69-165.

Timasheff, S. N., Witz, J. \& Luzzati, V. (1961). Biophys. J. 1, 525-537.

Zachau, H. G. (1969). Angew. Chem. Internat. Edit. 8, $711-727$. 